\title{
Burkitt's Lymphoma Mimicking a Subacute Subdural Hematoma: a Case Report
}

\section{Linfoma de Burkitt simulando um hematoma subdural subagudo: relato de caso}

\author{
Lucidio Duarte de Souza Filho ${ }^{1}$ João Tiago Alves Belo ${ }^{2}$ Pedro Henrique Martins Cunha ${ }^{2}$ \\ Rodrigo Moreira Faleiro ${ }^{3}$
}

${ }^{1}$ Hospital São Francisco; Hospital da Polícia Militar, Belo Horizonte, MG, Brazil

2 Neurosurgery Residency, Hospital Felicio Rocho and Fundação Hospitalar do Estado de Minas Gerais (FHEMIG), Belo Horizonte, MG, Brazil

${ }^{3}$ Hospital Felício Rocho; Neurosurgery and Neurology, Hospital João XXIII, Belo Horizonte, MG, Brazil

Address for correspondence Rodrigo Moreira Faleiro, MSc, Rua Caraça, 518/201, Serra, Belo Horizonte, Minas Gerais, Brazil 30220260 (e-mail: r.m.faleiro@hotmail.com).

\section{Abstract \\ Keywords \\ - burkitt's lymphoma \\ - subdural hematoma}

Burkitt's lymphoma (BL) is a highly aggressive B cell non-Hodgkin lymphoma. Although dural metastases are relatively frequent in malignancies, they are rarely associated with subdural hematoma (SDH). We present a case of subdural effusion secondary to dural metastases from Burkitt's lymphoma.

O linfoma de Burkitt é um linfoma Linfoma não Hodgkin de células B altamente agressivo. Embora a presença de infiltração meninges seja relativamente comum no contexto de neoplasias malignas o surgimento de hematoma subdural secundários é evento raro. Será relatado caso de coleção subdural secundaria a metástases dural de linfoma de Burkitt que apresentou-se radiologicamente semelhante a hematoma subdural em fase subaguda.

\section{Introduction}

BL is a B cell non-Hodgkin lymphoma that may affect multiple organs. It presents predominantly in children and is one of the most rapidly growing tumors in humans requiring immediate diagnosis and treatment. ${ }^{1}$

Dural metastases mimicking a SDH are rare. $^{2}$ We describe a case of central nervous system involvement characterized by subdural effusion radiologically similar to subacute SDH. We also review the relevant literature on this topic.

received

September 30, 2015

accepted

December 21, 2015

published online

March 4, 2016

\section{Case Report}

A 21-year-old male with Down syndrome presented to the emergency department with a seven-day headache associated with nausea and a significant deterioration in the last 48 hours. There was no report of trauma. Besides these symptoms, there was a recent urological investigation of orchiepididimitis due to pain and swelling in the scrotum. On neurological examination the patient was alert, confused, and agitated, without motor deficit or meningeal signs.

Copyright $\odot 2016$ by Thieme-Revinter Publicações Ltda, Rio de Janeiro, Brazil 
Computed tomography (CT) imaging of the brain revealed a right-side large heterogenous subdural fronto-temporo-parietal collection with mass effect, midline shift, and a right parietal subgaleal effusion (-Fig. 1). The platelet counts, prothrombin, and activated partial thromboplastin time were normal.

Due to the clinical presentation and mass effect evident on the CT scan, the patient underwent an urgent surgical procedure (right frontal and parietal bur hole trephination) with the presumptive diagnosis of subacute subdural hematoma. The drained fluid was hypertensive and xanthochromic. The patient had remission of symptoms. A brain CT performed on the second postoperative day showed improvement of the midline shift.

After ten days, he became symptomatic again (headache). A repeated CT scan of the brain revealed recurrence of the rightsided subdural collection with severe mass effect and midline shift. Empyema was hypothesized and we conducted a frontotemporo-parietal craniectomy extended from the bur holes with drainage collection and gathering material for microbiological studies. A dural biopsy was also performed. Broadspectrum antibiotic therapy (Meropenem and Vancomycin) was initiated, with partial improvement of symptoms. By this time, his urologic workup revealed the presence of atrophic orchiepididimitis on the left with testicular nodules. The alphafetoprotein and $\beta$-HCG were normal. LDH found was $1292 \mathrm{U} / \mathrm{L}$ (normal range: 338- $610 \mathrm{U} / \mathrm{L}$ ).

There was no bacterial growth on culture. Histological and immunohistochemical examination revealed typical pattern of Burkitt's lymphoma ( - Fig. 2). On the $19^{\text {th }}$ day, the patient developed progressive worsening and gingival bleeding, decreased level of consciousness, and left hemiparesis. CT

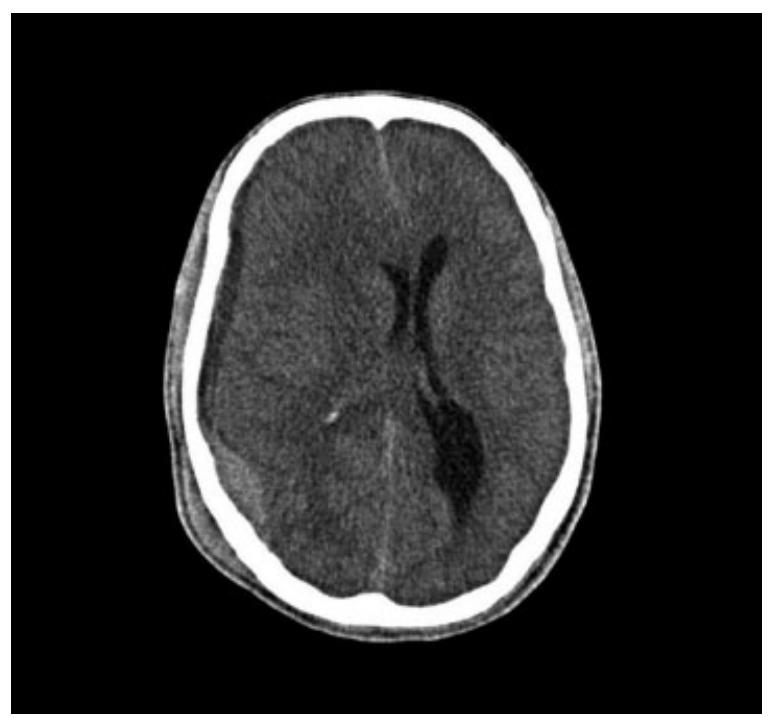

Fig. 1 Admission CT scan. This examination demonstrates a heterogeneous crescentic fluid collection enlarged and extended over the surface of the right cerebral hemisphere. The fluid was suggestive of subacute subdural hematoma. The midline structures of the brain were shifted to the left side. It is still possible to observe a right hiperdense subgaleal effusion that was similar to a subgaleal hematoma.

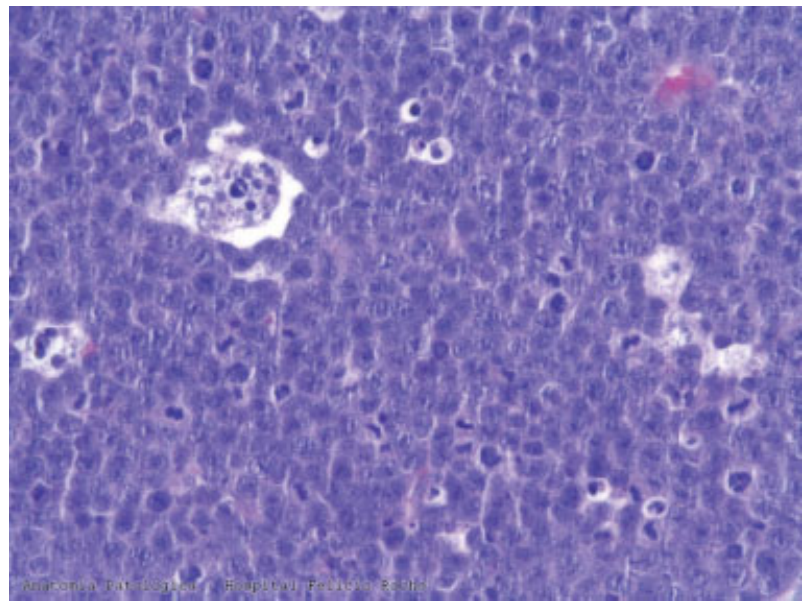

Fig. 2 Photomicrography of the bone marrow's histological examination. The bone marrow examination shows medium-sized cells with abundant basophilic cytoplasm, often containing lipid vacuoles; round nuclei with clumped chromatin and multiple nucleoli; and a diffuse, monotonous pattern of infiltration, the proliferative rate is elevated; frequent apoptoses, and numerous macrophages containing ingested apoptotic tumor cells conferring a starry sky" appearance to the microscope slide, typical finding of BL (stained with hematoxylin and eosin, 40-fold increase).

scan showed severe cerebral edema and expanded decompressive craniectomy was performed.

Oncology staging was performed with chest, abdomen, and pelvis computed tomography demonstrating infiltration of abdominal organs (pancreas, liver, and spleen) as well as cervical lymph node involvement. The bone marrow workup revealed the presence of blasts in "starry sky". HIV sorology was negative.

The patient received systemic chemotherapy with dexamethasone, vincristine, and cyclophosphamide. He developed sepsis and died on the $32^{\text {nd }}$ day of hospitalization.

\section{Discussion}

Classically, lymphomas are divided into Hodgkin's lymphoma and non-Hodgkin's lymphoma (NHL). In 5-9\% of systemic NHL, CNS involvement usually occurs in the form of leptomeningeal infiltrates. ${ }^{3}$ Parenchymal lesions, when present, typically result from secondary involvement via infiltration of the perivascular spaces from the leptomeninges. ${ }^{4}$

BL is a highly aggressive NHL and it is characterized by C-MYC gen translocation. It is probably the fastest growth malignancy that affects humans. ${ }^{1}$ It can double in size in 24 hours with $80 \%$ of its cells in mitosis at any point. ${ }^{5}$ Histologically, BL is characterized by diffuse infiltration of monomorphic medium-sized neoplastic cells with basophilic cytoplasm and numerous mitotic figures. Nuclear contours are round or oval without cleaves or folds. Nucleoli are typically multiple, small-to-intermediate in size, and the nuclear chromatin is relatively immature, being finely granular. Also high is the rate of cell death or apoptosis, with the dead cells being taken up by pale histiocytic cells within the tumor, which punctuate the low-power view giving a "starry sky" appearance. ${ }^{1,5,6}$ 
Three clinical variants of BL are recognized: Sporadic BL, Endemic BL, and Immunodeficiency-associated BL. Sporadic $\mathrm{BL}$ is seen throughout the world, mainly in children and adolescents and manifests itself especially with abdominal masses. The endemic form usually appears with a large mandibular or facial mass. There is a preferential involvement of the bone marrow and lymph nodes in the Immunodeficiency-associated form. CNS involvement is most found in Sporadic and Immunodeficiency-associated BL forms ( $\sim 13-17 \%$ of cases). In North America or Europe, where CNS disease tends to occur in patients with systemically advanced disease, particularly when there is bone marrow involvement, the prognosis is usually worse. In contrast, a significant proportion of patients with CNS involvement in Africa have a limited disease. ${ }^{1,7}$

Primary and secondary cases of dural involvement lymphomas are usually situated in places rich in meningothelial cells, and result in a localized mass or a plaque-like thickening of the dura that radiologically resembles other diseases that may respond to surgical treatment, such as meningioma or $\mathrm{SDH}^{8}$

Dural metastases have been found in $~ 8-9 \%$ of patients who died of cancer, in most autopsy series. ${ }^{9}$ The pathophysiology of the spread of extracranial malignancies to the dura can be related to the direct extension of calvarial metastases to the dura, or a combination of both arterial and venous spread. ${ }^{10}$ Non-traumatic SDH secondary to dural metastases is a rare but well-documented event. Several hypotheses have been proposed. First, the bleeding could be due to the rupture of fragile tumor neo-vessels. Second, expanding skull metastases could cause mechanical obstruction of external dural vessels, leading to the dilatation and eventually the rupture of the capillaries of the inner dural layer. Finally, chronic subdural hematoma could be the mediator rather than a consequence of subdural invasion. ${ }^{9}$

Large cohort studies have concluded that there were two main groups of SDH in these patients: (1) SDH related to predisposing factors (such as previous head trauma, alcoholism, or anticoagulation) and (2) spontaneous nontraumatic $\mathrm{SDH}$. The two groups were found both in solid tumors and in hematological malignancies, but the first group was more frequently associated with solid tumors, while spontaneous hematoma was mainly associated with hematological malignancies. ${ }^{11}$ A variety of coagulation disorders in cancer patients arise from tumor-specific growth characteristics, neo-angiogenesis with impaired endothelial lining, defective myelopoiesis, hypoproteinemia, or metastatic lesion growth with organ dysfunction. ${ }^{9}$ In our case, the subgaleal swelling was misdiagnosed as a traumatic etiology of the SDH.

Computed tomography (CT) or magnetic resonance (MR) imaging can be confusing, as the underlying etiology may be masked by the SDH, or the appearance can simulate meningiomas. In our case, we interpreted the presence of subdural and subgaleal hyperdense lesions as acute bleeding, although they were probably were solid infiltration of dura mater and galea. The signal intensity of a lymphoma on MR images is nonspecific. ${ }^{4}$ We did not perform preoperative MR imaging in our case due to rapid neurological deterioration.

Patients with SDH and a history of malignancy should be investigated for metastatic disease and coagulation disorders. If both are found, the prognosis is likely to be dismal. If surgery is performed, the subdural membrane and SDH should be sent for histopathology. This is essential for diagnostic and prognostic purposes. If there is recurrence of the SDH, revision surgery should be undertaken only with the knowledge that the prognosis is very poor without it. ${ }^{9}$ As the surgical approach and prognosis of SDH and metastatic tumors are completely different, the differential diagnosis is very important.

In summary, the case presented in this paper was misdiagnosed as a subdural hematoma, and shows the importance of including lymphoma in the differential diagnosis of subdural effusions. A high index of suspicion for malignancy should be maintained in approaching cases with non-traumatic SDH, especially if it is recurrent, even in the absence of obvious primary malignancy or radiological evidence of dural metastases.

\section{References}

1 Molyneux EM, Rochford R, Griffin B, et al. Burkitt's lymphoma. Lancet 2012;379(9822):1234-1244

2 Ambiavagar PC, Sher J. Subdural hematoma secondary to metastatic neoplasm: report of two cases and a review of the literature. Cancer 1978;42(4):2015-2018

3 Goetz P, Lafuente J, Revesz T, Galloway M, Dogan A, Kitchen N. Primary low-grade B-cell lymphoma of mucosa-associated lymphoid tissue of the dura mimicking the presentation of an acute subdural hematoma. Case report and review of the literature. J Neurosurg 2002;96(3):611-614

4 Slone HW, Blake JJ, Shah R, Guttikonda S, Bourekas EC. CT and MRI findings of intracranial lymphoma. AJR Am J Roentgenol 2005; 184(5):1679-1685

5 Jan A, Vora K, Sándor GKB. Sporadic Burkitt's lymphoma of the jaws: the essentials of prompt life-saving referral and management. J Can Dent Assoc 2005;71(3):165-168

6 Perkins AS, Friedberg JW. Burkitt lymphoma in adults. Hematology Am Soc Hematol Educ Program 2008; *..: 341-348

7 Blum KA, Lozanski G, Byrd JC. Adult Burkitt leukemia and lymphoma. Blood 2004;104(10):3009-3020

8 Gocmen S, Gamsizkan M, Onguru O, Sefali M, Erdogan E. Primary dural lymphoma mimicking a subdural hematoma. J Clin Neurosci 2010;17(3):380-382

9 George KJ, Lau A, Ellis M, Kiehl T-R, Fehlings MG. Metastatic coagulopathic subdural hematoma: A dismal prognosis. Surg Neurol Int 2012;3:60

10 Zheng JX, Tan TK, Kumar DS, Lim LC, Loh HL. Subdural haematoma due to dural metastases from bronchogenic carcinoma in a previously well patient: an unusual cause of non-traumatic recurrent intracranial haematomata. Singapore Med J 2011; 52(4):e66-e69

11 Comănescu A, Roşca E, Bota M, Ninulescu G. Chronic subdural hematoma in a patient with acute myeloid leukemia and dural metastatic infiltration. Rom J Morphol Embryol 2008;49(2): 259-262 